\title{
Experimental Investigation of Self-Curing Properties of Polymer Modified Concrete
}

\author{
Mahdi Mobarak Koozehkanani ${ }^{1}$, Nima Jamshidi ${ }^{1}$, Soheil Rezapour ${ }^{1}$, Payam Kazemi Ashtiani ${ }^{1}$ \\ 1 Fiteon Construction Solution Co. \\ Unit 5, No. 8, Rahi Moeiri St., Fatemi Ave., Tehran, Iran \\ koozehkanan@fiteon.ir; n.jamshidi@fiteon.ir; soheil.rezapour@fiteon.ir; kazemi.ashtiani@fiteon.ir
}

\begin{abstract}
In this paper, the curing process of the concrete modified by a liquid polymer in different percentages are investigated, and the self-curing property is observed in polymer percentages of 6 and above. Polymer produces a layer on the surface of the cement and aggregate mortar and fills the small pores inside it, resulting in a considerable reduction in the permeability of the concrete. As the polymer layer forms on the outer layers of the concrete in a relatively short time, it prevents the water inside the concrete from evaporation. For the experimental investigations, 24 tests with 8 concrete cubes in different water-to-cement ratios and cement content of 350 $\mathrm{kg} / \mathrm{m}^{3}$ were carried out in the temperature of $25^{\circ} \mathrm{C}$. The polymer percentages of 0, 2, 4, 6, 8, 10 and 12 were used. From the 8 specimens in each test, half were kept in the water and the rest in the ambient air. By conducting compression tests, we found that keeping the cubes into the water or air does not make a noticeable influence on the curing. Moreover, due to their low permeability, we expect these concretes to be suitable for applications in very cold or very hot weathers.
\end{abstract}

Keywords: polymer-modified concrete, self-curing, curing, compression strength.

(C) Copyright 2021 Authors - This is an Open Access article published under the Creative Commons Attribution License terms (http://creativecommons.org/licenses/by/3.0). Unrestricted use, distribution, and reproduction in any medium are permitted, provided the original work is properly cited.

\section{Introduction}

Curing has a significant impact on the final properties of the hardened concrete. The role of the curing is to reduce the evaporation of water and to keep sufficient moisture in the concrete for the process of hydration, especially during the primary stages. However, in many cases, it is not possible to prepare the required conditions for the curing. Lack of facilities, execution problems, faulty supervision and even lack of

Date Received: 2020-12-05

Date Accepted: 2020-12-11

Date Published: 2021-03-03 water in some countries are some examples for barriers against ideal curing.

With progresses in the concrete technology in the last two decades, solutions have been offered for improvement of the concrete quality, one of which is the internal curing. The amount of mixing water in the design of the concrete mixture is usually more than the amount necessary for the hydration. The extra water in the mixture design is spent to enhance the quality of the fresh concrete. If this extra water could be kept into the concrete and inhibit its evaporation, the internal curing would take place. The internal curing provides several advantages such as an increase in hydration and strength, reduction of spontaneous contraction and hence preventing from cracking, reduction of permeability and enhancement of the durability. Based on the previous researches, the internal curing in the ordinary concretes are accomplished by the use of saturated lightweight aggregates and superabsorbent polymer. In these methods, the absorbed water is gradually used by the cement paste during the hydration process.

In the present research, experiments have been conducted on PMC samples to investigate the effect of additive polymer on the enhancement of compression strength with and without curing. It has been tried to examine whether the use of polymer is effective on the self-curing property of the concrete and whether the PMC should be categorised into the self-curing concretes.

\section{Literature Review}

El-Dieb et al. [1] in 2011 studied the use of polyethylene glycol and polyacrylamide polymers as the self-curing materials, and by investigating the microstructure of the concrete, they showed that these 
materials - if used alone or together- improve the mechanical and durability properties of concrete during the self-curing process. Mousa et al. [2] in 2015 studied the mechanical specifications of self-cured concrete specimens by replacing a portion of concrete aggregates by Leca Lightweight Aggregates and also by using an internal curing agent (polyethylene glycol) in various water to cement ratios and different cement contents. They conducted experiments and showed that in the studied specimens, the concrete properties are improved compared with the witness samples. They reported the optimum values to be replacing $10 \%$ of the sand with Leca or using $2 \%$ weight polyethylene glycol in the cement.

The extra internal water can be used for the cement during the hydration process if the water is prevented from leaving the concrete by blocking the capillary passages in the surface of the concrete in the early stages. This process occurs in the polymermodified concrete by using water-soluble polymers such as acrylic (PAE) copolymers, styrene-acrylic (S-A) copolymers and styrene-butadiene (S-B) copolymers. Polymer modified concrete (PMC) is a mixture of cement with organic resins with the ability to diffuse into the water. The added polymer offers benefits such as increased resistance during freezing-melting cycles, resistance against erosion, increased bending and tensile strengths, reduced permeability and elasticity module. Liquid resins with the capability of diffusing in water have been used as additives to mortar and hydraulic cement concrete for several years. These additives are named as polymer modifiers.

The usage of mortars modified by natural latex resins was increased during the 1920s and 1930s. In 1932, Band [3] suggested using artificial latex resins. Rodwell [4] in 1939 claimed for the first time that artificial latex resins such as polyvinyl acetate could be used for polymer-modified concretes. From the late 1940s, mixtures modified by polymer have been employed in different applications such as covering the bridge and ship deck, paving and anti-erosion and anticorrosion flooring.

Many researches have been carried out in relation to the mixture design and mechanical properties of the PMC. Geist et al. [5] in 1953 conducted a comprehensive study on the modification of the mortars with polyvinyl acetate. Regarding the application of the polymer in concrete, Blaga and Beaudoin [6] in 1985 studied the properties of PMC. Their experiments showed that such concretes have lower permeability, higher resistance against aggressive chemicals and higher resistance against melting and freezing compared with the ordinary concretes. Walters [7] in 1992 demonstrated that styrene-butadiene latex improves the bending strength and resistance against permeability as the ratio of polymer to cement is increased. Kardon [8] in 1997 provided a comprehensive review over the accomplished investigations until that time about PMC, its properties and the effect of various polymers and ratios on its mechanical properties. Ohama [9] in 1998 reviewed various polymer additives used in PMC and explained their effect on the properties of the fresh and hardened concrete. In 1999, ASTM published the ASTM C 1438 standard [10] in which the specifications of the latex and polymer modifiers for hydraulic cement mixture and the methodology of polymer-modified mortars are specified.

Kuhlmann [11] in 1984, investigated the time and method of wet curing for PMC and examined its effect on the amount of permeability by the chlorine-ion experiment. There are not many researches on the quality and the method of PMC curing and since the use of these concretes is growing, elimination of the curing process or decreasing its time offer benefits such as cost reduction, acceleration in the construction process and avoidance of the problems specific for the places where curing is difficult.

\section{Methodology}

For the study of the self-curing property of PMC, a polymer with the specifications shown in table 1 was used as the modifier and specimens with the condition according to table 2 were used. As is reported in the table, percentages of polymer were $0,4,6,8,10$ and 12 , and 4 different water to cement $(\mathrm{W} / \mathrm{C})$ weight ratios were examined. The standard ASTM C33 was followed for preparation of the aggregate.

The impact of polymer modifier amount and water to cement ratio on the self-curing property of PMC was investigated in 24 tests. In each test, 8 cubic samples with dimensions $15 \times 15 \times 15 \mathrm{~cm}^{3}$ were prepared. The samples were kept into the mould for one day, then were taken out and were kept in the air for another day to allow the polymer on the surface to dry. Half of the samples were kept into the water in $25^{\circ} \mathrm{C}$ and the other half were exposed to air in $25^{\circ} \mathrm{C}$. Then, the compression strength of the samples was measured to investigate the effect of eliminating the wet curing process on the PMC in the ages of 7 and 28 days. The ambient humidity in all tests was almost $50 \%$. For the compression tests, a standard 
calibrated machine was used whose expanded uncertainty U95 (coverage factor $\mathrm{k}=2$ ) was less than $4 \%$.

The main sources of errors in our results are thought to be due to fluctuations in the temperature and humidity of the environment and potential differences in the sizes of sand grains used in different samples. However, those factors are controlled in our tests, and their effects are limited. In all, because of the provisions made in the tests and measurements as mentioned above, we expect to attain reliable results.

Table 1. The specifications of the polymer.

\begin{tabular}{|l|c|}
\hline Polymer modifier & Fiteon C Fitstick 50 \\
\hline Monomers & styrene-acrylic \\
\hline $\begin{array}{l}\text { Minimum temperature } \\
\text { of film formation }\end{array}$ & $0^{\circ} \mathrm{C}$ \\
\hline Specific density & 1.02 \\
\hline Solid percentage & $50 \%$ \\
\hline
\end{tabular}

Table 2. The conditions of the concrete specimens and type of curing. The cement content in all cases is $350 \mathrm{~kg} / \mathrm{m}^{3}$.

\begin{tabular}{|l|l|l|l|l|l|}
\hline No & $\begin{array}{l}\text { Test } \\
\text { tag }\end{array}$ & W/C & $\begin{array}{l}\text { polymer } \\
\text { content } \\
(\%)\end{array}$ & $\begin{array}{l}\text { curing } \\
\text { type }\end{array}$ & $\begin{array}{l}\text { lubricant } \\
\text { additive }\end{array}$ \\
\hline 1 & $55 \mathrm{Cu}$ & 0.55 & $\begin{array}{l}0,4,6,8, \\
10,12\end{array}$ & Wet & - \\
\hline 2 & $55 \mathrm{Na}$ & 0.55 & $\begin{array}{l}0,4,6,8, \\
10 \& 12\end{array}$ & Not wet & - \\
\hline 3 & $50 \mathrm{Cu}$ & 0.50 & $\begin{array}{l}0,4,6,8, \\
10 \& 12\end{array}$ & Wet & - \\
\hline 4 & $50 \mathrm{Na}$ & 0.50 & $\begin{array}{l}0,4,6,8, \\
10 \& 12\end{array}$ & Not wet & - \\
\hline 5 & $45 \mathrm{Cu}$ & 0.45 & $\begin{array}{l}0,4,6,8, \\
10 \& 12\end{array}$ & Wet & - \\
\hline 6 & $45 \mathrm{Na}$ & 0.45 & $\begin{array}{l}0,4,6,8, \\
10 \& 12\end{array}$ & Not wet & - \\
\hline 7 & $40 \mathrm{Cu}$ & 0.40 & $\begin{array}{l}0,4,6,8, \\
10 \& 12\end{array}$ & Wet & $\begin{array}{l}\text { Poly } \\
\text { naphthalene } \\
1.0 \%\end{array}$ \\
\hline 8 & $40 \mathrm{Na}$ & 0.40 & $\begin{array}{l}0,4,6,8, \\
10 \& 12\end{array}$ & Not wet & $\begin{array}{l}\text { Poly } \\
\text { naphthalene } \\
1.0 \%\end{array}$ \\
\hline
\end{tabular}

\section{Results and Discussion}

The properties of the polymer modifiers are functions of two processes, the concrete hydration and coalescence of the polymer. Beeldens et al. [12] in 2004 used a numerical model to investigate the micro and macro structures of the PMC in different stages of the cement hydration and polymer film formation, and studied the effect of their interaction in achieving the modified properties for the concrete. In the internal parts of the concrete, the hydration usually occurs in the beginning. When the cement particles are hydrated, the setting process happens, and the concrete is hardened. Subsequently, the polymer particles are concentrated in the resulting void spaces. While the amount of water is continuously reduced due to the cement hydration, evaporation or both, the polymer particles are hardened and form a layer of polymer which encompasses the hydrated cement. Consequently, a polymer mixture covers the aggregates and fills the empty spaces. In PMC, the polymer particles which are generally $100 \mathrm{~nm}$ or larger, gradually infiltrate into the capillary passages formed in the cement mortar. The polymer particles reduce the rate and amount of the moisture evaporation by blocking the capillary passages. Moreover, when very small cracks form, the polymer film acts as a bridge on the cracks and inhibit their further development.

In the outer parts, surface evaporation occurs, and polymer starts to form a film before the concrete begins to set, and a layer of the film covers the outer surface of the concrete. This film helps keep some of the internal moister needed for the rest of the hydration process. As a result, the required water for curing is lower than the case that ordinary concrete is used.

The results for the compression strength in the ages of 7 and 28 days are displayed in the figures 1 and 2 for different water to cement ratios and two cases of with and without curing. As the figures illustrate, in both cases of with and without curing, the compression strength of the samples is increased when smaller water to cement ratios are used. However, with higher percentages of the polymer modifier, the compression strength declines in general. In higher water to cement ratios and with small amounts of polymer percentage, this decline is more obvious. For example, compared to the zero polymer percentage, adding $8 \%$ polymer leads the compression strength to decrease by more than $50 \%$. When high water to cement ratios are applied, the strength is increased by using greater amounts of polymer percentages. 


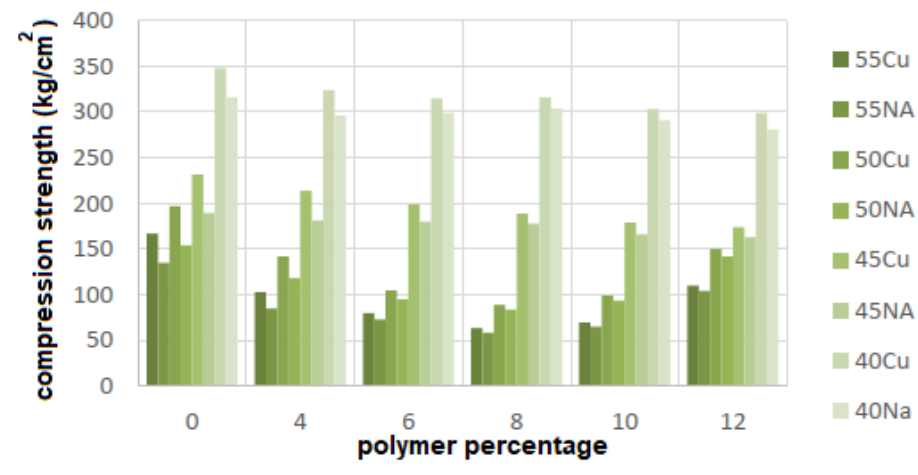

Figure 1. The experimental results for the specimens in the age of 7 days in different polymer percentages.

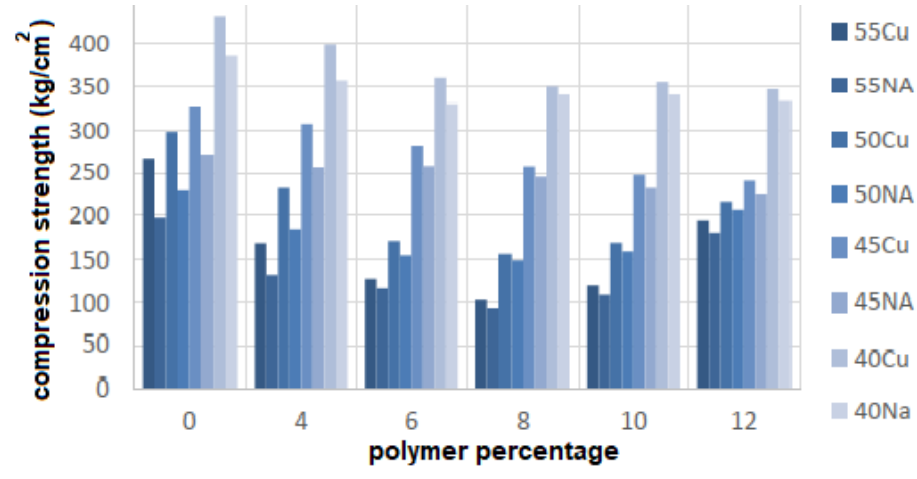

Figure 2. The experimental results for the specimens in the age of 28 days in different polymer percentages.

From the figures, it is also seen that in the water to cement ratios smaller than 0.45 , the decline in the compression strength is gradual as the polymer percentage is increased. However, in the water to cement ratio of 0.4 , a dramatic rise is seen with respect to higher ratios, which is due to the usage of the lubricating additive.

In similar water to cement ratios, compared to the conditions with curing, the compression strength declines when no curing is applied. The decline becomes lower as more polymer is used. For more accurate scrutiny, the percentage of the strength reduction in the samples in the cases with and without curing are compared in figures 3 and 4 for the sample ages 7 and 28 days respectively. As is seen, with increasing the percentage of polymer modifier, the reduction in strength is decreased from $20 \%$ to $5 \%$. The reduction of the strength is almost stabilised in $5 \%$ when the polymer percentage of 8 or more is used.

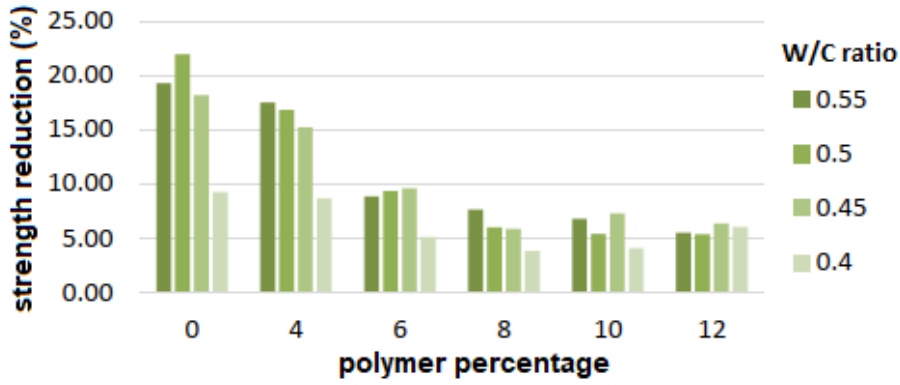

Figure 3. The reduction in strength for the specimens without curing with respect to the specimens with curing in the age of 7 days.

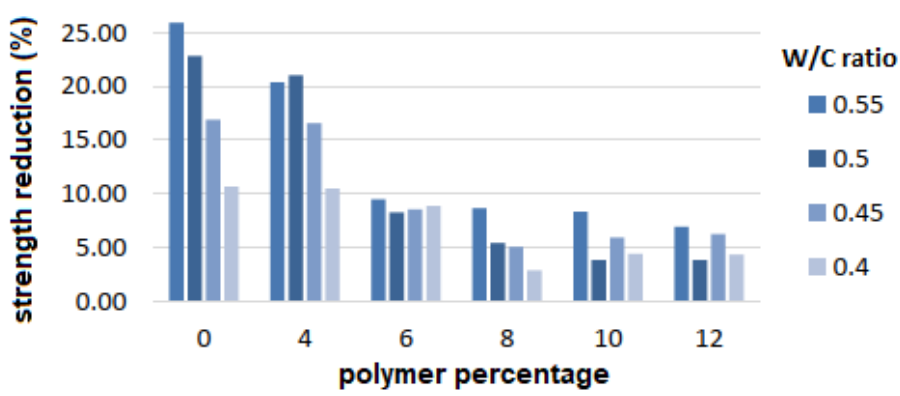

Figure 4. The reduction in strength for the specimens without curing with respect to the specimens with curing in the age of 28 days.

The strength reductions related to the water to cement ratio are noticeable in the polymer percentages lower than 6. As the ratio of the water to cement is reduced, the percentage of the strength reduction is smaller, but that is not the case in polymer percentages less than 6.

\section{Conclusion}

By reducing the ratio of water to cement, the volume of capillary passages inside the concrete becomes less. As a result, the capacity of the concrete for keeping water grows and hence, the decline in the strength related to the removal of the curing process is moderated. By adding polymer to the concrete, the film formed on the outer surfaces in the early stages blocks the passages and helps keep the internal moisture into the concrete. As the polymer percentage is increased, the mentioned decline in the strength is moderated and from a certain point (about 8\% polymer), further increase in the polymer percentage does not provide a significant improvement which is thought to be because of saturation, meaning that no additional blockage can occur in the capillary pores and the capacity of the internal water for internal curing is limited. 
By using more than $6 \%$ polymer in the concrete, internal curing occurs which leads some amount of free water to be available for the cement not still hydrated and hence, the hydration process carries on even without wet curing. Therefore, one can regard the polymer-modified concrete as self-curing. The concretes with more than $8 \%$ polymer do not show noticeable differences comparing to lower percentages, although they may have impacts on other mechanical and durability parameters which have not been investigated in this work.

\section{Acknowledgements}

We appreciate Morteza and Nader Mirzaei from Sarouj Sazan Almas Co., Ebrahim Moghaddam from Beton Morvarid Amertat Co. and Masoud and Majid Shirvanibaghshahi from Apadana Dena Beton Co. for providing us with test facilities for this research. Furthermore, we appreciate Mehdi Seddiq from Swansea University for his comments on the paper.

\section{References}

[1] A. S. El-Dieb, T. A. El-Maaddawy and A. A. M. Mahmoud, "Water-soluble polymers as self-curing agents in cement mixes," Advances in Cement Research, vol. 24, no. 5, pp. 291-299, 2012.

[2] M. I. Mousa, M. G. Mahdy, A. H. Abdel-Reheem and A. Z. Yehia, "Mechanical properties of self-curing concrete (SCUC)," HBRC Journal, vol. 11, no. 3, pp. 311-320, 2015.

[3] A. E. Bond and R. Critchley Ltd, British Patent 369,561, March 17, 1932.

[4] A. G. Rodwell, German Patent 680,312, August 29, 1939.

[5] J. M. Geist, S. V. Amagna, and B. B. Mellor, "Improved Portland Cement Mortars with Polyvinyl Acetate Emulsions," Industrial and Engineering Chemistry, vol. 45, no. 4, pp. 759-767, 1953.

[6] A. Blaga, and J. J. Beaudoin, "Polymer modified concrete," Ottawa: National Research Council Canada, 1985.

[7] D. G. Walters, "The Effect of Polymer Variables and Other Parameters on the Properties of PolymerModified Cement Mixtures," in Polymer-Modified Hydraulic-Cement Mixtures, ASTM STP 1176, L. A. Kuhlmann and D. G. Walters, Eds. West Conshohocken, PA: ASTM International, 1992.

[8] J. B. Kardon, "Polymer-modified concrete: review," Journal of Materials in Civil Engineering, vol. 9, no. 2, pp.85-92, 1997.
[9] Y. Ohama, "Polymer-based admixtures," Cement and concrete composites, vol. 20, no. 2, pp.189-212, 1998.

[10] ASTM C1438-13, "Standard Specification for Latex and Powder Polymer Modifiers for use in Hydraulic Cement Concrete and Mortar," ASTM International, West Conshohocken, PA, 2013.

[11] L. A. Kuhlmann, "The Effect of Cure Time on Chloride Permeability of Latex-Modified Concrete," Dow Chemical Company, Midland, Michigan, 1984.

[12] A. Beeldens, D. Van Gemert, H. Schorn, Y. Ohama and L. Czarnecki, "From microstructure to macrostructure: an integrated model of structure formation in polymer-modified concrete," Materials and structures, vol. 38, no. 6, pp. 601-607, 2005. 